\title{
A PRIMARY APPROACH IN UNDERSTANDING THE BASIC ACCOMPLISHMENTS AND FUNCTIONING OF THE NUTRITION REHABILITATION CENTRES IN THE TELANGANA STATE
}

\author{
S. VAHINI \& K. UMA DEVI
}

Department of Foods \& Nutrition, College of Home Science, Professor Jayashankar Telangana State

Agricultural University (PJTSAU), Saifabad, Hyderabad, India

\begin{abstract}
Malnutrition is a silent emergency and it is one of the most common causes of morbidity and mortality among children and adolescent throughout the world. Severe acute malnutrition (SAM) continues to be the reason for increasing hospitalization and also a major killer disease. The study shows the primary approach in understanding the basic accomplishments and functioning of the Nutrition Rehabilitation Centres in the Telangana State. A total of 60 under-five children were selected from $12 \mathrm{NRCs}$ in Telangana State using purposive sampling technique. A questionnaire was used to collect data. Frequency distribution of treatment outcomes was calculated using descriptive statistics. From the studies and related analysis, it can be concluded that Nutritional rehabilitation Centre programme is highly effective and is supplementing the remedial and rehabilitation measures among the community remarkably well.

KEYWORDS: Severe Acute Malnutrition \& Nutritional Rehabilitation Center
\end{abstract}

Received: Jun 13, 2018; Accepted: Jul 17, 2018; Published: Jul 30, 2018; Paper Id.: IJASRAUG201814

\section{INTRODUCTION}

Malnutrition in children, particularly severe acute malnutrition (SAM), increases the risk of death from common childhood illnesses and contributes to $45 \%$ of deaths in children under five years of age (WHO, 2016a). Globally, as of 2016, an estimated 52 million preschool-age children were wasted, of which 17 million were severely wasted (UNICEF/WHO/World Bank, 2017). The majority of these children live in Asia, particularly Southern Asia were wasting has become a critical public health problem with a sub-regional rate of $15.4 \%$.

Severe acute malnutrition is defined by a very low weight for height (below $-3 z$ scores of the median WHO growth standards), by visible severe wasting, or by the presence of nutritional oedema. It afflicts an estimated 8.1 million under-five children in India. Nearly 0.6 million deaths and 24.6 million DALYs (disability-adjusted life years) are attributed to this condition. Although the median under-five case fatality rate of severe acute malnutrition typically ranges from $30 \%$ to $50 \%$, it can be reduced substantially when physiological and metabolic changes are taken into account. Management of severe acute malnutrition, according to WHO guidelines reduced the case-fatality rate by $55 \%$ in hospital settings and recent studies suggest that commodities such as ready-to-use therapeutic foods can be used to manage severe acute malnutrition in community settings. Severe acute malnutrition is a major public health issue.

Severe acute malnutrition is an important preventable and treatable cause of morbidity and mortality in children below five years of age in India. A number of state governments have taken the lead and are in the process 
of scaling up the establishment of Nutrition Rehabilitation Centers (NRCs) with the intention to improve the quality of care being provided to children with SAM and to reduce child mortality.

Nutrition Rehabilitation Center (NRC) is a special unit in a health facility where children with Severe Acute Malnutrition (SAM) are admitted and services are dedicated to the initial management and nutrition rehabilitation. Children are admitted as per the defined admission criteria and provided with medical and nutritional therapeutic care. Once discharged from the NRC, the child continues to be in the nutrition, rehabilitation program till she/he attains the defined discharge criteria for the program. At a District Hospital/ Medical College Hospital, the NRC should have 10-20 beds, depending on the size of that ward. The unit should be in a distinct area within the health facility and should be in proximity to the pediatric ward/in-patient facility (Government of India, 2011).

There is a need for evaluation of one of the ongoing nutrition intervention programme like NRCs, initiated in the recent past, so as to take necessary steps to overcome problems in implementation and to take corrective measures for better monitoring and for fruitful improvement in nutritional status of beneficiaries.

\section{METHODOLOGY}

\section{Sample Selection}

A total of 12 Nutrition Rehabilitation Centers (NRCs) of Telangana State were selected. From each NRC 5 children total of 60 children was selected for the present study by adopting the purposive sampling method.

\section{Questionnaire}

A structured questionnaire was prepared and used for the present baseline study.

\section{Survey Method Adopted}

Personal interview method of data collection was applied to collect data from targeted respondents (mothers or caregivers) to understand the basic accomplishments and the functioning of the Nutrition Rehabilitation Centers.

\section{Data Analysis}

The results of the collected data were statistically analyzed by using tabular and simple percentage method (Snecdor and Cohran, 1983).

\section{RESULTS AND DISCUSSIONS}

Table 1: The Criteria for Admission as an Inpatient

\begin{tabular}{|c|c|c|c|}
\hline \multirow{2}{*}{ SI.No. } & \multirow{2}{*}{ The Criteria for Admission as Inpatient (6-59 Months) } & \multicolumn{2}{|c|}{ No.of Children $(\mathrm{N}=60)$} \\
\hline & & Number & $\%$ \\
\hline $\mathrm{a}$ & Mid upper arm circumference (MUAC) $<115 \mathrm{~mm}$ or $11.5 \mathrm{~cm}$ & 3 & 5 \\
\hline $\mathrm{b}$ & $\begin{array}{l}\text { Weight for height }(\mathrm{WFH})<-3 \mathrm{SD} \text { with or without any grade of } \\
\text { oedema }\end{array}$ & 38 & 64 \\
\hline $\mathrm{c}$ & $\begin{array}{l}\text { Bilateral pitting oedema }+/++(\text { children with oedema }+++ \text { always } \\
\text { need inpatient care) }\end{array}$ & 0 & 0 \\
\hline $\mathrm{d}$ & MUAC $<115 \mathrm{~mm}$ and WFH $<-3 \mathrm{SD}$ & 11 & 18 \\
\hline \multirow[t]{2}{*}{$\mathrm{e}$} & MUAC $<115 \mathrm{~mm}, \mathrm{WFH}<-3 \mathrm{SD}$ and oedema & 2 & 3 \\
\hline & \multicolumn{3}{|c|}{ The Criteria for admission as inpatient $(<6$ Months) } \\
\hline $\mathrm{f}$ & $\begin{array}{l}\text { Infant is too weak or feeble to suckle effectively (independently } \\
\text { of his/her weight for length) }\end{array}$ & 3 & 5 \\
\hline $\mathrm{g}$ & Weight for length (WFL) $<-3$ SD (In infants $>45 \mathrm{~cm}$ ) & 0 & 0 \\
\hline
\end{tabular}




\begin{tabular}{|c|l|c|c|}
\hline \multicolumn{3}{|c|}{ Table 1: Contd., } \\
\hline $\mathrm{h}$ & Visible severe wasting in infants $<45 \mathrm{~cm}$ & 3 & 5 \\
\hline $\mathrm{i}$ & Presence of oedema both feet & 0 & 0 \\
\hline
\end{tabular}

Table (1) shows admission criteria for SAM children into the NRCs. Sixty-four percent of children were admitted into NRC due to weight for height (WFH) < -3SD with or without any grade of oedema, 5\% were mid-upper arm circumference $(\mathrm{MUAC})<115 \mathrm{~mm}$ or $11.5,18 \%$ were admitted for both the reasons of MUAC $<115 \mathrm{~mm}$ and WFH $<-3 \mathrm{SD}, 3 \%$ had MUAC $<115 \mathrm{~mm}$, WFH $<-3 \mathrm{SD}$ and oedema,5\% were admitted due to the infant being too weak or feeble to suckle effectively, and $5 \%$ were admitted by visible severe wasting in infants $<45 \mathrm{~cm}$.

Table 2: The Complications were Observed in the Child

\begin{tabular}{|c|l|c|c|}
\hline \multirow{2}{*}{ SI.No } & \multicolumn{1}{|c|}{ Complications } & \multicolumn{2}{c|}{ No.of Children (N=60) } \\
\cline { 2 - 4 } & \multicolumn{1}{|c|}{ Number } & \% \\
\hline a & Anorexia (Loss of appetite) & 10 & 17 \\
\hline b & Fever (39 degrees C) or Hypothermia (<35 C) & 12 & 20 \\
\hline c & Not alert, very weak, apathetic, unconscious, convulsions & 13 & 21 \\
\hline d & $\begin{array}{l}\text { Any other general sign that a clinician thinks requires admission for } \\
\text { further assessment or care }\end{array}$ & 7 & 12 \\
\hline e & Fever and severe dehydration based on history and clinical examination & 7 & 12 \\
\hline f & Anorexia and Hypoglycemia & 7 & 12 \\
\hline g & Anorexia, persistent vomiting and severe anemia & 4 & 6 \\
\hline
\end{tabular}

After the perusal of the table (2), various complications were observed in NRC admitted inpatient cases. Among the admitted people, those suffering from anorexia (loss of appetite) were $17 \%$, fever $\left(39^{0}\right.$ degrees $\left.\mathrm{C}\right)$ or hypothermia (<35 C) were $20 \%$, not alert, very weak, apathetic, unconscious and convulsions were observed in $21 \%$ of admitted people, $12 \%$ were admitted with general sign that a clinical expert thinks the child required admission for further assessment or care, $12 \%$ were admitted with fever and severe dehydration based on history and clinical examination, $12 \%$ anorexia, and hypoglycemia and 6\% were observed with anorexia (loss of appetite), persistent vomiting and severe anemia.

Table 3: Underlying Causes of Malnutrition were Observed in the Child

\begin{tabular}{|c|c|c|c|}
\hline \multirow{2}{*}{ SI.No } & \multirow{2}{*}{ Underlying Causes of Malnutrition } & \multicolumn{2}{|c|}{ No.of Children $(\mathrm{N}=60)$} \\
\hline & & Number & $\%$ \\
\hline $\mathrm{a}$ & Low socio-economic status & 8 & 13 \\
\hline $\mathrm{b}$ & Illiteracy & 3 & 5 \\
\hline $\mathrm{c}$ & Frequent infections & 6 & 10 \\
\hline d & $\begin{array}{l}\text { Inadequate food intake, low socio-economic status, } \\
\text { poor sanitation and illiteracy }\end{array}$ & 4 & 7 \\
\hline e & $\begin{array}{l}\text { Inadequate food intake, low socio-economic status, } \\
\text { poor sanitation and ignorance of family members }\end{array}$ & 7 & 12 \\
\hline $\mathrm{f}$ & $\begin{array}{l}\text { Inadequate food intake, low socio-economic status } \\
\text { and illiteracy }\end{array}$ & 6 & 10 \\
\hline $\mathrm{h}$ & $\begin{array}{l}\text { Low socio-economic status, poor sanitation and } \\
\text { illiteracy }\end{array}$ & 13 & 22 \\
\hline $\mathrm{i}$ & $\begin{array}{l}\text { Inadequate food intake, low socio-economic status, } \\
\text { poor sanitation, illiteracy and frequent infections }\end{array}$ & 9 & 15 \\
\hline $\mathrm{j}$ & $\begin{array}{l}\text { Inadequate food intake, low socio-economic status, } \\
\text { poor sanitation, unavailability of health services } \\
\text { and frequent infections }\end{array}$ & 4 & 6 \\
\hline
\end{tabular}

The underlying causes of malnutrition were detailed in the table (3). Thirteen percent of the admitted people were suffering from malnutrition due to low socioeconomic status, $5 \%$ due to illiteracy, $10 \%$ were by reason of frequent 
infections, $7 \%$ were suffering due to inadequate food intake, low socio-economic status, poor sanitation, and illiteracy. Twelve percent of the admitted people were suffering from malnutrition due to inadequate food intake, low socioeconomic status, poor sanitation and ignorance of family members. Ten percent of the people admitted in NRC were because of inadequate food intake, low socio-economic status, and illiteracy. $22 \%$ were suffering from malnutrition because of low socioeconomic status, poor sanitation, and illiteracy. Fifteen percent were suffering from malnutrition due to inadequate food intake, low socio-economic status, poor sanitation, illiteracy and frequent infections. Due to inadequate food intake, low socio-economic status, poor sanitation, unavailability of health services and frequent infections $6 \%$ were suffering from malnutrition respectively.

Table 4: Evaluation of the Functioning of the Nutritionist-Cum-Counsellor

\begin{tabular}{|c|l|c|c|}
\hline \multirow{2}{*}{ SI.No } & \multicolumn{1}{|c|}{ Evaluation of the Functioning of the Nutritionist -Cum-Counsellor } & \multicolumn{2}{|c|}{ Yes (N=60) } \\
\cline { 3 - 4 } & & Number & \% \\
\hline a & Was the child condition explained & 57 & 95 \\
\hline b & Whether explained about the type of treatment planned & 49 & 82 \\
\hline c & Obtaining admission in NRC is easy & 39 & 65 \\
\hline d & Is there any payment for admission & 38 & 63 \\
\hline e & Disease classified into any grade & 58 & 73 \\
\hline f & Does the NRC provided a good environment to stay & 54 & 97 \\
\hline g & Are you aware of type treatment being offered & 59 & 98 \\
\hline h & Whether the MO examined the client at the time of admission & 57 & 95 \\
\hline i & Whether the MO examined the child daily & 54 & 90 \\
\hline j & Whether the MO is prescribing the medical treatment to the child & 58 & 97 \\
\hline k & Is monitoring \& progress of the child recorded every day & 54 & 90 \\
\hline l & Are the individualized therapeutic diets planned \& charted out by nutritionist & 57 & 78 \\
\hline m & Were you explained about therapeutic diets & 56 & 93 \\
\hline n & Was the food made and served hygienically & 58 & 97 \\
\hline o & Whether the nutritionist monitor diet preparation every day & 55 & 92 \\
\hline p & Whether the anthropometric measurements are taken regularly & 55 & 92 \\
\hline q & Whether they making low cost locally available energy dense food & 58 & 97 \\
\hline r & Whether they following cooking methods with minimal nutrient losses & 58 & 97 \\
\hline s & Structured play therapy & 43 & 72 \\
\hline t & Were you given opportunity to prepare therapeutic diets & 47 & 78 \\
\hline u & Were the children given the stimulating toys to play & \\
\hline
\end{tabular}

As per table 4, out of 60 attendants of the children, 57 were explained about the condition of their admitted child, 49 were explained about the type of treatment planned, 39 were told that obtaining admission in NRC was easy, 38 attendants were told that there was some payment required for admission. The disease was classified into different grades according to 44 attendants of the admitted children. Almost everyone in the study sample felt that the NRCs had provided a good environment to stay. As per GOI, 2011 guidelines NRC should have a cheerful, stimulating environment; it should be child-friendly. Walls can be brightly painted and decorated. Ward should have sufficient space for all mothers/caregivers staying with the children to sit together and be given cooking and feeding demonstration. Except for six of them, the remaining all was aware of the type of treatment being offered at NRC. Except for two of them, everyone was glad to see that their wards were examined by the MO at the time of admission. Out of 60 attendants, yet again 57 were pleased to see that their wards were examined by the Medical Officer on a daily basis, 54 respondents stated that MO gave them a prescription. According to 58 attendants, the monitoring and progress of the children were done at NRC. Out of 60 attendants, 54 had knowledge about the type of therapeutic diets planned for their children. About $7 \%$ of the mothers had no knowledge about the food made and served hygienically at NRC, and a good93\% of them had knowledge. Out of 60 
attendants, 58 responded positively that the nutritionist had monitored the diet preparation every day. Ninety-two percent responded positively that the anthropometric measurements were taken regularly. They were making low cost - locally available energy dense food with respect to 55 attendants. Out of 60 respondents, 58 felt that they were cooking with minimal nutrient losses, 58 attendants stated that there was structured play therapy for admitted children. Out of 60, 43 were given the opportunity to prepare therapeutic diets. Forty-seven attendants expressed that their children were given the stimulating toys to play during their stay at NRC.

Table 5: The Present Category of Malnutrition in Children

\begin{tabular}{|c|l|c|c|}
\hline \multirow{2}{*}{ SI.No } & \multirow{2}{*}{ Category of Malnutrition } & \multicolumn{2}{|c|}{ No.of Children (N=60) } \\
\cline { 3 - 4 } & & Number & \% \\
\hline A & Mild malnourished & 19 & 32 \\
\hline B & Moderately malnourished & 14 & 23 \\
\hline C & Severely malnourished & 27 & 45 \\
\hline
\end{tabular}

Table (5) shows the category of malnutrition in which the admitted child at present. Thirty-two percent were mild, $14 \%$ moderately malnourished and $27 \%$ were the severely malnourished category.

Table 6: Screening Test Regularly was done at NRC

\begin{tabular}{|c|l|c|c|}
\hline \multirow{2}{*}{ SI.No } & Screening Test & \multicolumn{2}{c|}{ No.of Children (N=60) } \\
\cline { 3 - 4 } & Regularly Done by & Number & \% \\
\hline a & Medical officer & 38 & 63 \\
\hline b & Nutritionist & 14 & 24 \\
\hline c & Nurse & 8 & 13 \\
\hline
\end{tabular}

From the above table (6), it can be observed that out of 60 children 38 client's families informed that the screening test was conducted by MO, 14 stated that Nutritionist did the screening test for admitted children, and 8 of them indicated that nurse used to do the screening part.

Table 7: Evaluation of Nutritional Treatment during the Stay at NRC

\begin{tabular}{|c|l|c|c|}
\hline \multirow{2}{*}{ SI.No } & \multicolumn{1}{|c|}{ Nutritional Treatment during the Stay } & \multicolumn{2}{c|}{ No.of Children (N=60) } \\
\cline { 3 - 4 } & Number & $\mathbf{\%}$ \\
\hline $\mathrm{a}$ & Nutrition screening of the child & 8 & 13 \\
\hline $\mathrm{b}$ & $\begin{array}{l}\text { Assessment of feeding problems \& Diet counseling } \\
\text { session to the mother }\end{array}$ & 7 & 12 \\
\hline $\mathrm{c}$ & $\begin{array}{l}\text { Nutrition screening of the child, assessment of feeding } \\
\text { problems and feeding of modified diets }\end{array}$ & 10 & 17 \\
\hline $\mathrm{d}$ & $\begin{array}{l}\text { Nutrition screening of the child, assessment of feeding } \\
\text { problems, feeding of modified diets and diet counseling } \\
\text { session to the mother }\end{array}$ & 35 & 58 \\
\hline
\end{tabular}

Table 7 shows the evaluation of nutritional treatment during the stay at NRC. All the clients were undergoing all the four types of treatment during the stay at NRC.

Table 8: Type of Diet Served Initially to the Client

\begin{tabular}{|c|l|c|c|}
\hline \multirow{2}{*}{ SI.No } & Type of Diet & \multicolumn{2}{|c|}{ No.of Children (N=60) } \\
\cline { 3 - 4 } & Served Initially & Number & \% \\
\hline A & Fluid & 26 & 43 \\
\hline B & Soft & 15 & 25 \\
\hline C & Semi Solid & 19 & 32 \\
\hline
\end{tabular}


According to $43 \%$ of the respondents, fluids were served initially, $25 \%$ stated that soft food was served and $32 \%$ respondents had told that they were served semi-solid food (Table 8).

Table 9: Medicines Given to the Clients

\begin{tabular}{|c|l|c|c|}
\hline \multirow{2}{*}{ SI. No } & \multirow{2}{*}{ Medical Treatment } & \multicolumn{2}{|c|}{ Yes (N=60) } \\
\cline { 3 - 4 } & & Number & \% \\
\hline 1 & Iron syrup & 60 & 100 \\
\hline 2 & Multi vitamin & 57 & 95 \\
\hline 3 & Folic Acid & 56 & 93 \\
\hline 5 & Zinc Sulphate & 54 & 90 \\
\hline 6 & ORS & 50 & 83 \\
\hline 7 & Anti biotics & 54 & 90 \\
\hline 8 & Chioamphenicol & 35 & 58 \\
\hline 9 & Contrimoxazola & 6 & 10 \\
\hline 10 & Genmycin & 8 & 13 \\
\hline 11 & Metronidazole & 8 & 13 \\
\hline 12 & Tetra cyclin & 5 & 8 \\
\hline 13 & Atropine & 3 & 5 \\
\hline 14 & I.V Fluids & 39 & 65 \\
\hline
\end{tabular}

From the above table 9, it is perceived that all the medicines were available at NRCs. According to the client's health condition, the medicines were given to the inpatients.

Table 10: Food Demonstration and Nutrition Counseling is given to the Clients

\begin{tabular}{|c|c|c|c|c|c|c|c|}
\hline \multirow{2}{*}{ SI.No } & \multirow{2}{*}{ Activity } & \multicolumn{2}{|c|}{ Nutritionist } & \multicolumn{2}{c|}{ Nurse } & \multicolumn{2}{c|}{ Cook Cum Attender } \\
\cline { 3 - 8 } & Number & $\%$ & Number & $\%$ & Number & $\%$ \\
\hline a & $\begin{array}{l}\text { Who will give the food } \\
\text { demonstration (N=60) }\end{array}$ & 33 & 55 & 13 & 22 & 14 & 23 \\
\hline b & $\begin{array}{l}\text { Who will provide } \\
\text { nutritional counseling }\end{array}$ & 55 & 92 & 5 & 8 & 0 & 0 \\
\hline
\end{tabular}

From the above table (10) nutritionists at NRCs had given food demonstrations according to 55\% of attendants, nurse to $22 \%$ of respondents and cook-cum-attender gave food demonstrations according to $23 \%$ of client's families. Except for $8 \%$ of them, the remaining $92 \%$ of the clients were provided nutrition counseling by nutritionists at NRC.

Table 11: The Visual Aids used for Nutrition Education

\begin{tabular}{|c|l|c|c|}
\hline \multirow{2}{*}{ SI.No } & \multicolumn{1}{|c|}{ Type of Visual Aids } & \multicolumn{2}{c|}{ No. of Clients (N=60) } \\
\cline { 3 - 4 } & \multicolumn{2}{|c|}{ Number } & \% \\
\hline A & Photos & 6 & 10 \\
\hline B & Charts & 21 & 35 \\
\hline C & Real foods & 7 & 12 \\
\hline D & Photos and charts & 8 & 12 \\
\hline E & Charts and real foods & 4 & 13 \\
\hline F & Charts and books & 5 & 7 \\
\hline G & Photos, charts and real foods & 2 & 3 \\
\hline H & Photos, charts, real foods, and books & & \\
\hline
\end{tabular}

Table (11) shows the visual aids used for imparting nutrition education to the client's families. Ten percent of attendants were provided nutritional education with the aids like photos, charts used for $35 \%$ of attendants, real foods for $12 \%$, photos \& charts to $12 \%$, charts and real foods for $13 \%$, charts and books to $7 \%$, photos, charts and real foods for $8 \%$ and maximum aids were used to educate $3 \%$ of the attendants. 
Table 12: Type of Counseling given to the Attendants

\begin{tabular}{|c|c|c|c|}
\hline \multirow{2}{*}{$\begin{array}{l}\text { SI. } \\
\text { No }\end{array}$} & \multirow{2}{*}{$\begin{array}{l}\text { Type of Nutritional } \\
\text { Counseling Given }\end{array}$} & \multicolumn{2}{|c|}{ No. of Clients $(\mathrm{N}=60)$} \\
\hline & & Number & $\%$ \\
\hline $\mathrm{a}$ & Individual counseling & 28 & 47 \\
\hline $\mathrm{b}$ & Group counseling & 19 & 32 \\
\hline $\mathrm{c}$ & $\begin{array}{l}\text { Individual \& Group } \\
\text { counseling }\end{array}$ & 13 & 21 \\
\hline & Topics Covered & & \\
\hline $\mathrm{a}$ & $\begin{array}{l}\text { Balanced diet \& } \\
\text { Malnutrition }\end{array}$ & 18 & 30 \\
\hline $\mathrm{b}$ & Hygiene \& Sanitation & 9 & 15 \\
\hline $\mathrm{c}$ & IYCF & 11 & 18 \\
\hline $\mathrm{d}$ & All & 22 & 37 \\
\hline
\end{tabular}

Concurring table 12, its seen that type of nutritional counseling given was individual counseling in accordance with $47 \%$, group counseling was provided for $32 \%$ of the attendants and both the group counseling and individual counseling was given for $21 \%$ of the attendants. Thirty percent of the attendants explained about the balanced diet and malnutrition, $15 \%$ were given education on hygiene \& sanitation, $18 \%$ on IYCF and $37 \%$ were covered with all the topics.

\section{CONCLUSIONS}

There is only one NRC at the each District Hospital for the entire erstwhile district that plays a major role in combating the issue of malnutrition but as the erstwhile district is big so the services are only utilized by the limited number of population. It would be of major help if such model is established at an area hospital on the other side of each district so that it will be reachable, and might even decrease the defaulter rate and dropouts.

As always, prevention is better than cure! What we need is the promotion of low- cost sustainable solutions like an optimal infant and young child feeding so that SAM does not occur. And encourage in preparation of nutritious diet with locally available energy-rich foods.

\section{REFERENCES}

1. Government of India. 2011. Operational guidelines on facility based management of children with severe acute malnutrition. Ministry of Health and Family Welfare.

2. Snecdor, G. W and Cohran, W. G. 1983. Statistical methods. Oxford and IBH publishing company, New Delhi.

3. Koula, Doukani, and Mimoun Hadjer. "Physico-Chemical and Nutritional Characterization Of Arbutus Unedo L. From The Region Of Tiaret (Algeria)."

4. UNICEF, WHO, World Bank. 2017. Level and trends in child malnutrition: Joint Child Malnutrition Estimates: Key findings of the 2017 edition.

5. WHO. 2016a. Children: reducing mortality (Fact sheet). Geneva, World Health Organization. 
